\title{
Balancing contested meanings of creativity and pathology in Parkinson's Disease
}

\author{
Dorothy Porter
}

\begin{abstract}
Introduction
Parkinson's Disease is one of the defining degenerative diseases of ageing populations. In 2005 there were an estimated 4.1 million sufferers worldwide, a figure projected to reach 8.7 million by $2030 .{ }^{1}$ However, those statistical projections have already been dramatically revised. Current estimates are that 7 to 10 million people in the world are affected, with estimates that this will double within a decade as economically developing and developed populations expand, age and chronically sicken. ${ }^{2}$ One million people live with Parkinson's in the United States, with a further 60,000 diagnosed each year; ${ }^{3}$ in Britain, a new person is diagnosed every hour. ${ }^{4}$ The disease is characterised by limb tremor and bradykinesia, along with signs such as fixed facial expression, lack of eye blinking, hoarse inaudible voice, shuffling gait, asymmetrical arm swinging and loss of physical balance not easily regained. Cognitive impairment can accompany progressive physiological decline, ending in frontal lobe dementia. ${ }^{5}$

A cure for Parkinson's still eludes us, even as hopes run high among the experimental scientific community. ${ }^{6}$ However, there has been a remarkable clinical managerial tool available from the 1960s, one that leverages dopamine substitution in brains where massive dopaminergic neuron death has triggered symptoms. ${ }^{7}$ The pharmacological breakthrough of L-DOPA transformed the experience of patients living with gradual decline in motor function, and assisted in reducing some of the
\end{abstract}


behavioural distress that can accompany the disease. L-DOPA was able to lift the spirits of some patients who had experienced at least a decade of suffocating clinical depression prior to diagnosis. Other successful pharmacological innovations in Parkinson's Disease management have extended the clinical arsenal. ${ }^{8}$ Among the most effective of these has been dopamine agonist therapeutics, which reduce the horribly disconcerting dyskinesias that can be produced by L-DOPA treatment and prevent uncontrollable jerky neck, arms and legs. Some of the medicines in the Parkinson's Disease apothecary's chest, however, have indeterminate consequences for behavioural transformations and thus therapeutic balance between motor improvement and emotional instability is key to the highly specialised therapeutic management of the disease in each case. Complex behavioural reactions to dopamine agonist treatments in particular have led to clinical caution regarding their use. ${ }^{9}$

This chapter investigates questions about balance in Parkinson's Disease by analysing historical shifts in debates about a predetermined behavioural model of a Parkinson's Disease personality, its relationship to artistic creativity and implications for therapeutic equilibrium in clinical management. The aim of the chapter is to demonstrate that focusing on balance merely in terms of therapeutic dosage plans ignores broader dimensions of balancing cultural conflict surrounding ontological and emergent meanings of the disease and the transcendent metaphysics of creativity. In this way it speaks directly to the central themes of this volume, which addresses the contingent scientific and clinical normativities of physiological and psychological balance and their relationship to models of the self. ${ }^{10}$ Drawing out the historical determinants of contingently normative neo-humoralism threaded through the story of Parkinson's Disease - evident in other manifestations of neurology ${ }^{11}$ - this chapter also explores an alternative, and equally ancient, narrative of balance about the dualism of creative genius. Roy Porter used William Blake's lament about the 'mind forg'd manacles' of the creative imagination to epitomise the eighteenth-century European Enlightenment's mirror of reason and madness. ${ }^{12}$ My task here is to examine how balancing drug reception in the brain is bound to the legacy of Enlightenment normative contingencies concerning madness and reason, genius and lunacy, creativity and manic compulsion. Before demonstrating how the history of Parkinson's Disease offers an opportunity to investigate 
shifting cultural epistemologies of the self as an ontological and emergent category, and the ways in which notions of balance were folded into studies of creativity in terms of stimulation and inhibition, the following section presents a brief history of the discovery of the disease, its causes and the emergence of an idea of a Parkinson's personality.

\section{From physical tremor to mental torpor}

The London physician from Hoxton Square, James Parkinson, described the experiences of six patients who all exhibited the definitive symptoms of what he termed 'the shaking palsy' in 1817: 'Involuntary tremulous motion, with lessened muscular power, in parts not in action and even when supported; with a propensity to bend the trunk forwards, and to pass from a walking to a running pace: the senses and intellects being un-injured. ${ }^{13}$

Parkinson did not include personality or behavioural characteristics in his analysis of etiology but attributed the cause to pathology of the spinal cord. ${ }^{14} \mathrm{He}$ described each patient as having a different life story, their ages ranging from their mid-fifties to early seventies. Parkinson included contrasting psychological profiles of his subjects, but did not offer cultural characterisations comparable to contemporary medical discourses on gout or tuberculosis. ${ }^{15}$ One patient, he recounted, was a gardener who had led a life of 'remarkable temperance and sobriety'. By contrast, a retired attendant at the magistrate's court attributed his condition to the 'consequence of considerable irregularities in his mode of living, particularly of indulgence of spirituous liquors. ${ }^{16}$

Parkinson's descriptions of impeded gait in all the patients he observed equally fascinated the founding father of modern neurology, Jean Martin Charcot, half a century later. ${ }^{17}$ Charcot worked and taught for thirty-three years at Paris' vast charity hospital, the Salpêtrière, ${ }^{18}$ where his lectures became public spectacles, most famously when he used hypnosis to illustrate his theories about the neurological character of hysteria. ${ }^{19}$ Charcot defined the clinical characteristics of multiple sclerosis, motor neuron disease and muscular dystrophy, and significantly expanded the neurological understanding of the Shaking Palsy, which he renamed Parkinson's Disease. ${ }^{20} \mathrm{He}$ differentiated resting tremor in Parkinson's from active tremor in multiple sclerosis. He also identified that patients with resting tremor exhibited rigidity and impaired ability to adjust bodily position, and slow movement (bradykinesia), 
that they had soft spoken voices and that movement alleviated their tremor. Throughout 1888 he studied and presented a patient, referred to as Bachere, to demonstrate and discuss the posture, stance and retropulsive and propulsive gait pathologies of Parkinsonism. ${ }^{21}$ Charcot pioneered the use of visual representation as a research and teaching tool and left sketches of Bachere's abnormal stance and gait along with observations of his fixed facial muscle 'mask. ${ }^{22}$ While Charcot's drawings constitute the first representation of the clinical symptoms of the disease, perhaps the most emblematic was sculpted by the artist anatomist Paul Richer, who was Charcot's assistant and head of the Salpêtrière laboratory from 1882-96, and who had sculpted a female patient because she represented 'the almost perfect clinical schema of Parkinson's Disease. ${ }^{23}$

Charcot's students and assistants began trying to uncover the causes of Parkinson's by suggesting that lesions in a small area in the mid-brain known as the substantia nigra compactica might be involved in the loss of muscle control. But it was a visitor to the Salpêtrière from Russia, Konstantin Tretiakoff - together with one of Charcot's students, Gheorghe Marinesco - who definitively demonstrated that destruction of cells in the substantia nigra was related to the onset of Parkinson's Disease, ${ }^{24}$ by dissecting the brains of patients who had died from a new form of encephalitis - known as Von Economo's encephalitis, after its discoverer - that appeared during the First World War. ${ }^{25}$ Following the war, a group of von Economo's patients developed Parkinsonism, and it was in the brains of fifty of these patients that Tretiakoff discovered marked loss of the dark melanin-pigmented neuron cells in the substantia nigra and noted that the remaining cells were damaged with pathological deposits he referred to as Lewy bodies. ${ }^{26}$

While Tretiakoff had identified that neuronal death in the substantia nigra was involved in causing Parkinson's, he could not explain how or why that anatomical destruction led to motor system dysfunction. That required moving beyond anatomical analysis to an examination of the chemical functioning of the brain and the role of dopamine, ${ }^{27}$ which was first synthesised at the Wellcome Laboratories in $1910 .^{28}$ At that time dopamine was believed to be a precursor of the catecholamine neurotransmitters responsible for chemically transmitting information between neurons in the brain. But the biological function of dopamine as a neurotransmitter itself was discovered by a Swedish pharmacologist, the Nobel Laureate Arvid Carlsson, in $1958 .{ }^{29}$ Carlsson made the 
discovery as the result of reanimating rabbits with the amino acid DOPA, stimulating the production of dopamine in the basal ganglia structures in the mid-brain, where motor function is located. Following this discovery, Carlsson and his colleagues announced at an international pharmacological meeting in 1959 that Parkinsonism was induced by dopamine depletion, which could be reversed by L-DOPA, ${ }^{30}$ and subsequently used new forms of fluorescence histo-chemistry to map dopamine pathways in the brain. Over the next three decades, Parkinson's research focused on refining the therapeutic application of L-DOPA and adjunct dopamine agonists to control motor symptoms of the disease. ${ }^{31}$ Such approaches were not unusual in this period: reconstructing physiological balance using metabolic hormones had been popular in the management of chronic illnesses since the early twentieth century. ${ }^{32}$

Carlsson and his team had originally sedated rabbits into a catatonic state with a neuroleptic drug, resperine. Neuroleptics are a class of major tranquillisers that have been used since the Second World War to control psychotic states such as schizophrenia, leading to the hypothetical postulate that dopamine variability - or imbalances - played a significant role in the development of schizophrenia and perhaps other forms of behavioural change. ${ }^{33}$ The dopamine hypothesis of schizophrenia and broader categories of psychopathology was contested throughout the latter half of the twentieth century, but the dopaminergic neurobiology of the brain became central to genomic research on cognitive and emotional variation from the 1990s. ${ }^{34}$

The discovery of dopamine in Parkinson's Disease not only provided an explanation of motor dysfunction, but also created an opportunity to examine psychological aspects of the disease and revived interest in the idea of a 'Parkinson's personality'. Carl Dudley Camp, Professor in Nervous Diseases at the University of Michigan, had first posited the idea of a Parkinson's personality in 1913. He had suggested on the basis of anecdotal observations that:

It would seem that paralysis agitans affected mostly those persons whose lives had been devoted to hard work ... The people who take their work to bed with them and who never come under the inhibiting influences of tobacco or alcohol are the kind that are most frequently affected. In this respect, the disease may be almost regarded as a badge of respectable endeavor. $^{35}$ 
Dudley Camp offered a psychological profile of Parkinson's patients as characteristically socially and personally responsible, in ways that echoed the associations made between gout and social elevation in the eighteenth century or between diabetes, class and social prominence from the late nineteenth century. ${ }^{36}$ In the 1980 s, a number of neurologists and psychiatrists, including Andrew Lees and G. M. Stearn at University College London, the London psychiatrist Cecil Todes (who had himself developed Parkinson's Disease at the age of 39) and the Austrian neurologist Werner Poewe, expanded the idea of a pre-morbid Parkinson's personality. ${ }^{37}$ The classic description offered by Todes and Lees in 1985 was that Parkinson's patients exhibited an emotional and attitudinal inflexibility, a lack of affect and a predisposition to depressive illness, which could antecede the development of motor abnormalities by several decades. ${ }^{38}$ Introspective, overcontrolled, anhedonic personality traits, together with suppressed aggression, were frequently found. However, it was unclear whether these behavioural patterns were relevant aetiological factors or prodromal symptoms of the disease. $^{39}$

At the same time as observational accounts were positing a Parkinson's personality, experimental biopsychologists were developing new tools for identifying biologically determined personality characteristics and types. ${ }^{40}$ In his 'unified biosocial theory of personality', in 1986, Claude Robert Cloninger, Kantian transcendentalist philosopherprofessor of psychiatry at Washington University, developed a system of 'tridimensional psychobiological temperament' measurement of correlations of catecholamine activity with personality traits of noveltyseeking, harm avoidance and reward dependence. ${ }^{41}$ The tridimensional temperament system provided a new methodological and epistemological framework for genomic correlation with personality and cognitive analysis. Cloninger first developed his methodologies for constructing predictive personality models when working in Sweden in the 1980s on alcohol dependence through 'separation studies' - that is, investigating cohorts of children separated from their biological parents at birth. ${ }^{4}$ By the end of the decade, he had codified his psychobiological temperament model in a Tridimensional Personality Questionnaire (TPQ) and a Tridimensional Character Inventory (TCI), tools that provided the neurobiology of cognition and character with a new framework of investigation. ${ }^{43}$ 
Cloninger's biological hypothesis of character and temperament resonated with investigations into genomic influences on dopaminedependent cognitive and emotional variation. ${ }^{44}$ From the earliest studies with twins, discourses on the inheritability of cognitive ability were embedded in the psychobiology of intelligence. Since the completion of the human genome map, the role of the dopaminergic system and its genetic variations have reframed this investigation. ${ }^{45}$ Since 2000, a number of candidate dopaminergic genes in cognitive variation have been explored, and $\mathrm{D} 2$ receptor polymorphisms have become central to genomic investigations of a subset of cognitive function, namely creativity. ${ }^{46}$ Dopaminergic variation currently occupies the central focus of neuromolecular analyses of creativity, defined and measured in terms of novelty-seeking divergent thought. Mesolimbic, or reward pathway, ${ }^{47}$ accounts of creativity have now gained sufficient confidence to begin claiming the capacity to be predictive. For example, Sapra, Beavin and Zak from Claremont Graduate University and Loma Linda Medical School in California recently claimed to have demonstrated what they believe is the gene combination that produces highly successful careers. ${ }^{48}$

Apart from facilitating the genomic investigation of cognitive creativity variation, Cloninger's tridimensional personality and character system has also been used in genetic investigations into emotional variation, especially psychobiological charting of dopaminergic pathways in personality trait characteristics of reward learning, novelty-seeking and pathological addiction, a development that influenced neuromolecular constructions of a pre-morbid Parkinson's patient personality. ${ }^{49}$

In line with modern preoccupations with 'personality types' as determinants of chronic disease, psychobiologists have characterised Parkinson's patients as possessing distinctive personality traits of industriousness, seriousness and inflexibility. ${ }^{50}$ Cloninger's tridimensional character framework has rescripted this characterisation profoundly, as his TPQ and TCI have become major methodological tools for identifying and investigating a pre-morbid Parkinson's personality in terms, not only of the onset of motor dysfunction, but also of progressive cognitive and behavioural transformation. In 1993, Matthew Menza and colleagues, from the Robert Woods Johnson Medical School in New Jersey, identified dopamine-related personality traits in Parkinson's Disease using Cloninger's TPQ. ${ }^{51}$ Menza et al. claimed that 
low novelty-seeking Parkinson's patients were reflective, stoic, slowtempered, frugal, orderly and persistent, but by contrast high-scoring on Harm Avoidance. In 1995, the Menza team claimed to be able to explain this correlation by confirming - through PET (positron emission tomography) scans of Parkinson's Disease patients - that low 18 F-Dopa striatal uptake correlated with low novelty scores. ${ }^{52}$

Although subsequent studies have argued that Menza's results could simply be demonstrating the effects of long-term medication on advanced Parkinson's Disease patients, the neuromolecular pursuit of the predisposed low creative, high harm-avoiding personality continued. In 2011, Graham Pluck then at Sheffield University and Richard Brown from Kings College London attempted to extend the temperament model of predisposed Parkinson's personality through a study on cognitive attention capacity. Using Cloninger's framework, Pluck and Brown claimed to have demonstrated a characteristic apathy in Parkinson's Disease patients that was unrelated to the depression and anxiety often associated with the disease. They claimed instead that high apathy scores were correlated with the characteristic cognitive function of the pre-morbid Parkinson personality, legitimising their claims by suggesting that historical studies - stretching back to Charcot's description of low motivation in patients with Parkinson's Disease - confirmed the existence of a pre-morbid Parkinson's personality. ${ }^{53}$

\section{Balancing cultures of creativity: pathological creativity}

According to neuromolecular biopsychological theory, when genetically predisposed low novelty-seeking Parkinson's personalities demonstrate creativity it is a pathological symptom, an assumption that has been reinforced over the last two decades. In 2001, Anette Schrag and Michael Trimble from University College London reported what they believed to be the first case of poetic talent being 'unmasked' by dopamine agonist treatment for Parkinson's. ${ }^{54}$ Their patient was aged 40 when he was first diagnosed with Parkinson's with a tremor in his left hand, dragging of left leg and dystonia of the left foot. As his symptoms increased, the patient started treatment with the dopamine agonist lisuride and L-DOPA at age 44 . His symptoms significantly improved, and within the first month of treatment he began writing poetry for the first time in his life, completing ten poems in the first year of treatment. His 
poems achieved significant publishing success, and he won a prize in the annual contest of the International Association of Poets. ${ }^{55}$

The patient had always considered himself intellectually inferior to his siblings and family generally, never having achieved an equivalent level of academic success. He did, however, have a maternal grandfather who was a published poet, and he was related to a well-known Irish poet. No other changes occurred until, after twelve years of treatment, the patient began to show symptoms of depression, aggressive and volatile behaviour, along with grandiose ideas, paranoid delusions, extreme circumstantiality, over-talkativeness and pressured speech. After various therapeutic adjustments the patient returned to a stable emotional and cognitive state, with sustained control of motor symptoms. Throughout this period, and to the end of his life, the patient continued to write and publish his poetry. Schrag and Trimble explored a wide range of possible explanations for their 'poet unmasked', including contradictory implications of the classic 'pre-morbid PD personality theory', but found none sufficiently satisfactory. They finally speculated that 'the effect of dopaminergic and serotonergic drugs, either through cognitive enhancement, increased perception or a hypomanic syndrome in addition to selective fronto-cortical dysfunction, led to the release of previously inhibited creative power in this patient. ${ }^{56}$

If Schrag and Trimble were only tentatively speculating that their patient's art was a form of hypomanic 'high', by the mid-2000s a more reductive neuropsychological explanation was being offered of visual art produced by patients with Parkinson's Disease. In 2005, Ruth Walker and colleagues at the Veterans Affairs Medical Center New York and NYU School of Medicine described a patient who had possessed pre-morbid undeveloped 'artistic tendencies' for sketching that dramatically changed seven years after beginning dopamine agonist therapy. ${ }^{57}$ At this point he started producing several pastel drawings a week - sometimes two a day. After moving to an assisted living facility he had even more time to devote to his art, but at the same time began to show hypersexual disinhibition in what they describe as 'excessive flirting with women on the street and asking residents and staff of his assisted living facility to pose nude for his artwork. ${ }^{58} \mathrm{His}$ disinhibition became controlled following what they describe as 'education', and his artwork began to be shown and sold in local galleries in the Bronx. In contrast to Schrag and Trimble, Walker et al. describe their patient's 
artistic productivity as a pathological symptom of compulsive disorder equivalent to the pathological gambling and hypersexuality associated with excessive dopamine stimulation. Thus, Walker's team identified their patient's creativity as the result of the overstimulation of the third dopaminergic pathway in the brain, which is responsible for reward learning, that can become pathologically transformed into compulsive addiction. ${ }^{59}$ The clinical reduction of creativity to chemical imbalance, as we will see later, has been dramatically challenged by patients' accounts of their experience. ${ }^{60}$

In 2006, Anjan Chatterjee, Roy Hamilton and Prin X. Amorapanth from the University of Pennsylvania were far more reluctant than Walker to reduce their patient's art to the ravages of Parkinson's Disease, even after considering the benefits and challenges of defining it as a compulsive obsessive disorder. ${ }^{61} \mathrm{CSD}$, the Chatterjee team's patient, was a 68 year-old graphic designer whose motor symptoms had progressed over fifteen years from 1992, while his agonist and L-DOPA medications had been adjusted to compensate. A psychologist encouraged CSD to start painting as a therapeutic activity to relieve his depression in 2002. While initially producing work derivative of Van Gogh, within a year he had begun producing uniquely original vibrant coloured pencil abstract works using fine regular lines. He used his right hand, in which his resting tremor was severe enough to significantly restrict his capacity to write. But his artistic work used large amplitude proximal movements - reaching rather than distal movements used in writing and grasping - that allowed him to feel 'a sense of bursting forth and tearing back walls. CSD expressed an urgency to produce, and utilised the sleep disruption produced by Parkinson's Disease to wake early and work. His complete immersion into a visual image prevented him, he noted, from working on more than one painting at a time. While Chatterjee et al. note that CSD's preoccupation with his art could be interpreted as a compulsive obsessive disorder equivalent to addictive gambling, they allow his own words to express its meaning for him:

The train has left the station and I have just been served a delicious dinner in the café car. The train is picking up speed so I have to eat fast so I can finish my meal before we get to the last stop and I have to get off. ${ }^{62}$ 
Using artistic creativity production as a measure of impulsive predisposition in Parkinson's patients has now become a standard clinical methodology. Although this has been challenged by the experience of patients themselves and patient advocacy organisations such as Parkinson's UK, which introduced the Mervyn Peake Awards for Parkinson's patients' artistic work in 2006, ${ }^{63}$ artistic work redefined as a Cloninger novelty-seeking category has become regarded as an addiction symptom within the dopaminergic reward pathway. One component of addictiveproneness has been identified by Petra Schwingenschuh and her team at UCL and the Queen Square Institute, London, in a professional artist prior to the diagnosis of Parkinson's Disease. When pre-morbid Parkinson's Disease patients defy the Cloninger/Menza stereotypical lowcreative, harm-avoiding profile, then they are likely to acquire 'dopamine dysregulation syndrome' during therapy - that is, self-overdosing and strategic deception to obtain more dopamine than they supposedly need. The Schwingenschuh team reported on four patients who had all been successful visual artists before diagnosis, and who developed dopamine addiction while being treated. 'Artists', they explained, 'require a certain stimulus and drive to produce new and creative work. In the cases described here, we suggest that the compulsive seeking of, and overdosing with, dopaminergic drugs may arise from the patients' need to fuel this drive and enhance their creativity. ${ }^{64}$

\section{Dopaminergic compulsion}

Biological explanations for pathological creativity have focused on the indeterminate effects of dopamine agonist treatments on a second dopaminergic pathway in the brain, the mesolimbic pathway, which runs from the ventral tegmental area to the ventral striatum in the mid-brain. This pathway deals with reward learning, and if overstimulated can develop pathologies resulting in compulsive behaviour. Agonist drugs stimulate dopamine receptors in the brain to inhibit some of the dysfunctional side effects of treatment for Parkinson's with L-DOPA. They were developed in the 1970s after a decade of failed pharmacological attempts to compensate for L-DOPA's shortfalls and adverse side effects. $^{65}$

L-DOPA was first developed by the Oxford-trained Viennese pharmacologist, Oleh Hornykiewicz. Following Carlsson's discovery of the 
true biological function of dopamine, Hornykiewicz and his research assistant $\mathrm{H}$. Ehringer examined levels of dopamine in the post-mortem nigrostriatal systems of the brains of those who had suffered from Parkinson's Disease. ${ }^{66}$ Having discovered the dramatic loss of nigrostriatal dopamine, Hornykiewicz persuaded Walter Birkmayer, an ex-SS officer who was now working at the Vienna Geriatric Hospital in Lainz, to administer L-DOPA to twenty Parkinson's Disease patients. ${ }^{67}$ L-DOPA is the naturally occurring L-isomer of the amino acid D, L-dihydroxyphenylalanine. In 1938, Peter Holz had discovered that the enzyme L-amino acid decarboxylase (DOPA) converts the biologically inert L-DOPA into the biologically active catecholamine dopamine. The discovery of enzymes and metabolic hormones for rebalancing physiological systems became a dominant avenue of scientific research from the early twentieth century, ${ }^{68}$ but Birkmayer was initially reluctant to use L-DOPA for Parkinson's Disease patients because he clung to his belief that reduction in hypothalamic serotonin was responsible for the condition. In 1961, however, Birkmayer agreed to intravenously administer $50 \mathrm{mg}$ of L-DOPA to a single patient, who dramatically improved, and then agreed to administer $150 \mathrm{mg}$ to twenty patients with moderate and severe Parkinson's Disease. Hornykiewicz and Birkmayer presented their results at the Viennese Medical Society in 1961, reporting that:

The effect of a single intravenous injection of L-DOPA in Parkinson's Disease was, in short, a complete abolition or substantial relief of akinesia. Bedridden patients who were unable to sit up, patients who could not stand up from a sitting position, and patients who, when standing, could not start walking, performed all these activities after L-DOPA with ease. ... The voiceless, aphonic speech, blurred by palilalia and unclear articulation, became forceful and clear again as in a normal person. ${ }^{69}$

From the outset, adjunct therapies such as the administration of a monoamine oxidase inhibitor (MAOI) were tried to improve the effects of L-DOPA, especially to counteract the 'wearing off' period resulting from the short half-life of two hours of the dopamine precursor. While scepticism persisted about the efficacy of L-DOPA, in the late 1960s George Costzias demonstrated the emphatic anti-Parkinsonian impact of increasing dosage over a prolonged period of time. In 1969, Costzias began mixing L-DOPA with a peripheral dopa decarboxylase inhibitor (MK485) which diminished the dosage needed to control symptoms, 
and also reduced nausea and anorexia experienced by patients taking the drug. ${ }^{70}$

Further experiments with dopa decarboxylase inhibitors were pursued for the next decade in an attempt to improve the impact of L-DOPA, but the most serious side effects of motor fluctuations, uncontrollable jerking movements, dyskinesias and loss of drug efficacy in some patients persisted. These issues were not effectively addressed until the development of dopamine agonist drugs.

Apomorphine synthesised from morphine was first used in 1884 to treat Parkinsonism in patients with Sydenham's chorea and experimental efforts to treat Parkinson's Disease. ${ }^{71}$ Although dopamine agonists synthesised from ergot were also experimented with to treat Parkinson's Disease from the end of the nineteenth century, it was in the 1960s that prolactin inhibitors, such as the ergot-derived bromocriptine, were shown to reduce dopamine turnover in hypothalamic and nigrostriatal dopaminergic neurons. ${ }^{72}$ These discoveries led, in the 1970s, to the introduction of ergot-derived dopamine agonists to stimulate post-synaptic dopamine receptors in order to overcome the therapeutic shortfalls of L-DOPA and compensate for the loss of pre-synaptic pigmented neurons in the substantia nigra. By the mid-1970s, a range of dopamine agonists were developed that effectively prolonged dopamine receptor stimulation. By the early 1990s five dopamine receptors had been discovered, ${ }^{73}$ and dopamine agonists such as bromocriptine, lisuride, pergolide and newer synthetic ergolines such as carboline were developed to produce prolonged stimulation as a monotherapy in early stage patients to provide a neuroprotective role. They were subsequently introduced as an adjunct therapy in increasingly advanced patients to overcome the adverse side effects of L-DOPA. Some nonergoline-derived agonists, such as ropinirole and pramipexole, were further developed both as monotherapies in early stage patients and for compensating for L-DOPA shortfalls and side effects in patients with more advanced disease. ${ }^{74}$

However, problems emerged with dopamine receptor stimulation beyond the nigro-striatal dopaminergic pathway. As Chang and Grace note, patients 'with Parkinson's Disease who are treated with dopamine agonists to compensate for depletion in the motor systems often develop dysfunctions in reward-based learning, including impulse control disorders. ${ }^{75}$ These developments, they argued, 'were directly linked to 
pathological behaviors ultimately leading to definitional addictions, in recent years attention has been drawn to a complex group of impulse control disorders such as pathological gambling, hypersexuality, and compulsive eating or shopping. ${ }^{76}$ These are usually triggered by dopamine agonist treatment and conceptualised as behavioral addictions associated with aberrant or excess stimulation of dopaminergic reward mechanisms. ${ }^{, 77}$

Chang and Grace have posited that this may result from more rapid degeneration of some dopaminergic neurons than others. Motor loss results from dopamine degeneration in the dorsal tier of the substantia nigra compactica (SNC). However, the ventral tier of the SNC and the ventral tegmental area (VTA) may be affected less. Thus dopamine replacement therapies such as L-DOPA and agonist treatments may result in overstimulation where differential dopamine loss has been less marked, especially in the ventral tegmental area of the brain: 'because the medial SNC and VTA system are relatively spared', they argue, 'intact neurons could be over-stimulated as the dopamine agonist works across the entire system, with the consequence that pathologically high levels of dopamine receptor stimulation in limbic regions could occur. Such over-stimulation may increase the likelihood of Parkinson's Disease patients to develop impulse control disorders, such as pathological gambling, compulsive shopping, and hypersexuality. ${ }^{78}$

\section{In search of therapeutic balance}

Clinical literature has increasingly emphasised the necessity of pursuing therapeutic balance in agonist treatment. ${ }^{79}$ When considering the new prescription or increasing the dose of a dopamine agonist, expected benefits in motor nervous control must be balanced against the increased latent risk of impulse control disorders as well as other potential serious side effects. An extensive discussion in the clinical literature has explored staged therapeutics in which agonist drugs are used as the sole treatment for patients in the earliest stages of Parkinson's Disease, with the aim that their known neuroprotective function could delay the degeneration of motor function. In patients at later stages of the disease, agonists are subsequently recommended as adjunct treatment for the control of dyskenisias and to prevent or delay the development of dementia. ${ }^{80}$ However, with regard to the control of the emergence of 
impulsive behavioural symptoms there is a lack of consensus other than the recommendation of 'fine-tuning': ${ }^{81}$

It would seem pragmatic to be particularly watchful in the higher risk groups - especially younger males, those with prior mood disorders, obsessive-compulsive behavior, or drug, alcohol, or substance abuse history, and there is a clear need to be proactive in including a close family member or their prime carer in this advice. ${ }^{82}$

As several chapters in this volume show, families were often important conduits for medical advice and chronic disease management in the twentieth century. In literature on Parkinson's Disease, patients and families were warned that withdrawal of agonist drugs, or transfer from one to another, needed to be gradual and closely reviewed for adverse effects. However, all agreed that there was a significant lack of evidence on which to develop protocols for clinical practice. ${ }^{83}$

The clinical dilemma and search for therapeutic balance - and the interpretation of key moments of transition in management and experience of illness - is acutely illustrated in cases in which creativity has been diagnosed as a compulsive disorder resulting from the adverse effects of D2 receptor stimulation. A case reported by Jaime Kulisevsky and his group in 2009 exemplified the dilemmas faced in agonist therapeutic management where creativity in a Parkinson's patient is diagnosed as a pathological compulsion or addiction. ${ }^{84}$ Noting earlier reports by Walker, Schrag and Chatterjee, Kulisevsky described a patient who was 47 years old; he was an amateur painter before being diagnosed with Parkinson's Disease, but his interest in art diminished after he was first medicated and became depressed with mild apathy. He retired from his employment, and nothing changed in his behavioural profile until two years later when the dopamine agonist cabergoline was added to his L-DOPA treatment. His motor symptoms significantly improved and he began painting again, but with a dramatically changed attitude towards his artistic endeavour. Prior to Parkinson's Disease he took months to complete a painting and his work was detailed and figurative, focusing on accurately depicting reality. Now he started to produce one painting a week, and his paintings grew more and more impressionistic, emphasising colour and light rather than detail. The patient explained the change as a need to 'express his refreshed inner emotions. ${ }^{85}$ Within 
nine months he painted every day and started showing and selling his work in local galleries.

Kulisevsky et al. focused, however, on what they perceived to be degeneration into addiction as the patient began to continue painting through the night and his work pattern became disruptive to his family. They considered that his dysphoric response to suggestions that he should stop painting was a symptom of addiction to the activity. According to Kulisevsky, the patient regarded his artwork as 'positive for him as he was able to move more easily and he felt emotionally relieved', and no other behavioral changes occurred such as hypersexuality, dopamine dysregulation syndrome or other impulsive behaviours. Because the team considered the patient's artistic focus socially disruptive, cabergoline was withdrawn over a period of six weeks, during which the patient notably decreased his artwork and became increasingly apathetic and depressed. ${ }^{86}$ They then increased L-DOPA, but the patient did not resume painting. Reinstituting cabergoline therapy at $4 \mathrm{mg}$ per day led to the patient painting again with the same intensity; when cabergoline was reduced to $2 \mathrm{mg}$ per day he stopped painting at night. The clinical team believed they had finally achieved the right therapeutic balance to manage what they interpreted as continuous dopaminergic stimulation through dopamine agonists producing 'a pathological usurpation of the neural mechanisms of creativity. ${ }^{87}$

\section{Balancing cultures of creativity: patients' meanings}

In contrast to the neurobiological pathologisation of Parkinson's Disease patient art as a form of hectic compulsion, narrative accounts by patients themselves describe their creative work as establishing a sense of calm, release and transcendence equivalent to the experience of meditative Zen. Patients' narratives describe the relationship of their illness and creative work as an opportunity to experience new ways of what it means to be human. For Parkinson's patients, the impact of the illness on their creativity is accounted for in terms of humanistic meaning rather than biologically coded spirituality.

Johanne Vermette is a Parkinson's Disease patient who is a professional artist, a mother and a physician at Montreal University. Vermette was diagnosed with Parkinson's Disease in her late thirties and believed 
that her painting style became enhanced after her diagnosis: 'The new style is less precise but more vibrant ... I have a need to express myself more. I let myself go, sometimes painting with enraged fingers. ${ }^{\text {'8 }}{ }^{\text {Ver- }}$ mette is familiar with the theoretical view about the influence of her medication on her imagination, but she perceives her practice of painting through the night as a way to manage the chronic insomnia that accompanies Parkinson's and allows her undisturbed time while her children sleep. She sums up the experience of enhanced creativity as: 'When I paint I'm in the best place, because I am only doing that. There's no planning, no hierarchy of actions, but just the urgency of living. ${ }^{89}$ Urgency to paint for Vermette is not characterised as compulsive addiction, but rather as calming release.

Similarly, in contrast to creativity defined as pathologically hectic compulsion in the neuropsychomolecular paradigm, Parkinson's patient Gwendoline Spurll, a haemotologist at McGill University, argues that artistic expression has given her a new Zen-like quality in her life generally and in her clinical practice, which is often commented on by her patients. ${ }^{90}$ Spurll began painting in 2003 prior to her Parkinson's Disease diagnosis, when she focused on expressing the desolation she had felt during a period of her life twenty years earlier while struggling with infertility. Following her diagnosis of Parkinson's Disease in 2005 she started to focus on the existential dialectics of the embodied perception of joy and dismay: ${ }^{91}$ dismay that her Parkinson's would one day force her to end her clinical career and probably leave her home, but joy that she would at least be able to paint, probably throughout the duration of her degenerative condition. ${ }^{92}$ 'Does painting affect my practice as a physician?', Spurll asks. 'I think so. My patients often describe my bedside manner as calm, even Zen.' Spurll accounts for this as a sort of transference of her own experience in sitting down with a blank canvas and starting to paint. For her it induces 'a calm state in my mind that removes me from the imperfections of my life - and it convinces me that patients can likewise accept whatever confronts them. Apparently this conviction is communicated to my patients through my calmness. ${ }^{93}$ Citing Sacks's discussion of the disruption of self-expression inhibition in neurological patients with lesions such as frontal lobe dementia, Spurll ponders whether this effect noted in Parkinson's patients was also happening to her. ${ }^{44}$ 'What does this mean?', Spurll asks, 'I don't know.' What she does know is that painting 'induces a flow state, and removes 
from my consciousness the constant knowledge of my physical limitations. It is like a meditation. It is my Zen. ${ }^{95}$

For another artist, Alan Babbitt, however, the relationship between his Parkinson's Disease and his creativity has nothing to do with therapeutics. For Babbitt, Parkinson's became an opportunity in much the same way as Henri Matisse described the impact of illness on his artistic life-world over a century ago: ${ }^{96}$ Parkinson's Disease stimulated the creation of an entirely new artistic genre which he calls tremor enhanced photography. ${ }^{97}$ Babbitt has been a locally renowned San Francisco Bay Area artist since the 1970s. His initial interest in photography stemmed from the transformative visual experience it gave him, having impaired vision from albinism, nystagmus, lazy eye and profound myopia. ${ }^{98}$

Babbitt makes fun of his 'addiction' to photography, admitting to becoming shamelessly 'high' on it, breaking trespass laws in order to feed his habit. When the movement disorders of Parkinson's began to appear for the first time in 2003, 'darkness filled my viewfinder. He lost interest in photography, rarely venturing out to shoot, and was bored with the results. One night on the Las Vegas Strip - 'of all places', he says in disbelief - 'I began to see the light ... I began to let the tremor have its way as I clicked the shutter. ${ }^{99}$ The experience was 'Whoa!! ... The visual gumbo of flashing lights, multi-tinted neon and watery reflections became wonderful smears, blurs and streaks of color. Now THIS was fun! ${ }^{100}$ Beyond the sheer exuberance of the work, Babbitt describes an epistemological shift in understanding photography and Parkinson's Disease: 'Liberated from the photo dogma of "still"ness and sharpness, I've experienced a rush of creative freedom like never before. Rules? Who needs rules?' ${ }^{101}$ Babbitt puts it this way: 'The damn disease has given me a terrific gift! ${ }^{102}$

\section{Conclusion}

According to Aristotle, 'There is no great genius without a tincture of madness. ${ }^{103}$ The complex relationship between creativity and cultural representations of pathological mentalities has a long contested history, from theories about epilepsy in the ancient world to investigations of schizophrenia and bipolar disorder in the twentieth and twenty-first centuries. ${ }^{104}$ In this chapter a new moment of that contested history between pathology and creativity - and the shifting balance between 
them in medical and patient understandings of illness - has been examined in the context of the artistic work of patients suffering from Parkinson's Disease.

Parkinson's Disease currently remains a neurodegenerative disease that has effective pharmacological management tools that relieve suffering, including L-DOPA and dopamine agonists. Elsewhere I have documented the experience of the disease in an era before L-DOPA, when acute suffering, decline and premature mortality resulted from disablements in motor function. ${ }^{105}$ However, as scientific understanding of the disease developed throughout the late twentieth century, Parkinson's Disease became less a singular nosological entity defined by motor nervous dysfunction than a cascading process of multi-layered biological and behavioural transformation. ${ }^{06}$ In a neuromolecular framework, the behavioural consequences of dopaminergic death, substitution and stimulation have increasingly preoccupied scientific and clinical discourses on pathology. Over the last four decades a neuropsychobiological model of a genetically predetermined Parkinson's personality emerged within these discourses, reinforced by biopsychological measurement tools such as Cloninger's tridimensional paradigm. The neuromolecularly predetermined Parkinson's Disease personality has been characterised as measurably low novelty-seeking, high harmavoiding, inflexible and apathetic. When the genetically predisposed low-creativity paradigm of the Parkinson's personality is disrupted by artistic expression in patients, it is therefore frequently interpreted clinically as a pathological symptom of excessive stimulation of dopamine receptors in the reward-learning mesolimbic pathway, producing compulsive behaviour and addiction. Creativity is redefined in this context as an unintended pathological behavioural by-product of therapeutic intervention.

The search for evidence-based 'best practice' in dopamine agonist treatments has therefore preoccupied clinical literature since their introduction, ${ }^{107}$ and has so far not moved beyond anecdotal protocols advocating flexibility or adaptive clinical management aimed at achieving a balance between motor function improvement and behavioural equilibrium. ${ }^{108}$ Clinical debates concerning balance and the regulation of artistic self-expression do not, however, address how the fuller dimensions of balance might be considered and explored. As this chapter has shown, the notion of therapeutic balance needs to be 
considered within broader discussions of the clash between patient experiences, scientific knowledge and clinical understanding. Neuromolecular psychobiological characterisations of the relationship between creativity and Parkinson's Disease have generated a counterculture represented in the narratives articulated by patients, according to which ontological stasis is replaced with emergence, changing the relationship between embodiment and becoming. As a result, sufferers have dispersed the materiality of disability by creating the meaning of shifting embodiments for themselves and others: for example by engaging, expressing and disseminating the contradictions of dread and subliminal exquisiteness through artistic work, thereby unfolding the consequences of the misfolding proteins that are causing their degenerative physical change. In Parkinson's patients' accounts of their experiences of creativity, Paul Longmore's vision of a new meaning of ability becomes a material possibility. ${ }^{109}$ For Parkinson's patients engaged in creative artistic work, the essentialist concept of disability disappears into limitless opportunities for creating meaning, not out of being but out of incessantly becoming human.

\section{Notes}

1 University of California, San Francisco, 'Projected worldwide increase in prevalence of Parkinson's disease in 2005 and 2030 (in million patients)', Statista website (2018), available at www.statista.com/statistics/215459/ projected-worldwide-increase-in-prevalence-of-parkinsons-diseas/, accessed 21 August 2019.

2 'Parkinson's Disease Statistics', Parkinson's News Today (2018), available at https://parkinsonsnewstoday.com/parkinsons-disease-statistics/, accessed 21 August 2019.

3 Parkinson Association of the Carolinas, Statistics on Parkinson's Disease (2018), available at www.parkinsonassociation.org/understandingparkinsons/, accessed 21 August 2019.

4 Parkinson's UK, The Incidence and Prevalence of Parkinson's Disease in the UK: Results from the Clinical Practice Research Datalink Summary Report (December, 2017), available at www.parkinsons.org.uk/about-us/mediaand-press-office, accessed 27 September 2019.

5 'Parkinson's disease', The Free Dictionary (2018), available at https:// medical-dictionary.thefreedictionary.com/parkinson $\% 27 \mathrm{~s}+$ disease, accessed 21 August 2019. 
6 D.-H. Choi et al., 'Therapeutic potential of induced neural stem cells for Parkinson's Disease', International Journal of Molecular Sciences, 18 (2017), 224.

7 O. Hornykiewcz, 'A brief history of L-DOPA', Journal of Neurology, 257 (2010) (Suppl 2), S249-52.

8 E. Tolossa et al., 'History of L-DOPA and dopamine agonists in Parkinson's Disease treatment', Neurology, 50 (1998) Suppl., S2-10; discussion S44-8.

9 S. Khanam and Y. H. Siddique, 'Dopamine: agonists and neurodegenerative disorders', Current Drug Targets, 19 (2018), 1599-1611; K. Radad et al., 'Short review on dopamine agonists: insight into clinical and research studies relevant to Parkinson's Disease', Pharmacological Reports, 57 (2005), 701-12.

10 See Chapters 2, 8 and 9 in this volume. On cultural normativity in biomedical discourse, see W. Ernst, History of the Normal and the Abnormal: Social and Cultural Histories of Norms and Normativity (London: Routledge, 2006).

11 S. Finger, Origins of Neuroscience: A History of Explorations into Brain Function (Oxford: Oxford University Press, 1994), p. 1. S. Jacyna and S. T. Casper (eds), The Neurological Patient in History (Rochester, NY: Rochester University Press, 2012).

12 R. Porter, Mind Forg'd Manacles: A History of Madness in England from the Restoration to the Regency (London: Penguin, 1990).

13 J. Parkinson, An Essay on the Shaking Palsy (London: Sherwood, Neely and Jones, 1817), p. 1.

14 Parkinson, An Essay, p. 19.

15 See R. Porter and G. S. Rousseau, Gout: The Patrician Malady (New Haven, CT: Yale University Press, 2001); R. Porter, 'Consumption: disease of the consumer society', in J. Brewer and R. Porter (eds), Consumption and the World of Goods (London: Routledge, 1994), pp. 58-84; S. Sontag, Illness as a Metaphor (New York: Farrar, Straus and Giroux, 1978); M. Jackson, The Age of Stress: Science and the Search for Stability (Oxford: Oxford University Press, 2013).

16 Parkinson, An Essay, pp. 9-19.

17 C. Goetz, 'Charcot on Parkinson's Disease', Movement Disorders, 1(1986), 27-32.

18 A. Hustvedt, Medical Muses: Hysteria in Nineteenth Century Paris (New York: W. W. Norton, 2011); M. Micale, 'The Salpêtrière in the age of Charcot: an institutional perspective on medical history in the late nineteenth century', Journal of Contemporary History, 20 (1985), 703-31. 
19 C. Goetz et al., Charcot: Constructing Neurology (New York: Oxford University Press, 1995).

20 Goetz, 'Charcot on Parkinson's Disease'.

21 C. Goetz, 'The history of Parkinson's Disease: early clinical descriptions and neurological therapies', Cold Spring Harbor Perspectives in Medicine, 1 (2011), 1-15.

22 Ibid., p. 5.

23 N. Ruiz-Gómez, 'The "scientific artworks” of Doctor Paul Richer', Medical Humanities, 39 (2013), 4-10, at p. 8.

24 A. Lees et al., 'The black stuff and Konstantin Nikolaevich Tretiakoff', Movement Disorders, 23 (2008), 777-83.

25 L. C. Triarhou, 'Constantin von Economo (1876-1931)', Journal of Neurology, 254 (2007), 550-1; Y. Kaya et al., 'Constantin von Economo (1876-1931) and his legacy to neuroscience', Child's Nervous System, 32 (2016), 217-20.

26 A. M. Rodrigues et al., 'Who was the man who discovered the "Lewy bodies”?', Movement Disorders, 25 (2010), 1765-73.

27 On the emergence of physiology, neurophysiology and neurendocrinology in the redefinition of neurological pathology, see Jackson, The Age of Stress.

28 S. Fahn, 'The history of dopamine and L-DOPA in the treatment of Parkinson's Disease', Movement Disorders, 23 (2008) Suppl. 3, S497-S508; O. Hornykiewicz, 'Dopamine miracle: from brain homogenate to dopamine replacement', Movement Disorders, 17 (2002), 501-8; D. L. Roe, 'From DOPA to Parkinson's Disease: the early history of dopamine research', Journal of the History of the Neurosciences: Basic and Clinical Perspectives, 6 (1997), 291-301.

29 'Arvid Carlsson', in L. R. Squire, A History of Neuroscience in Autobiography, Volume 2 (New York: Academic Press, 1998), pp. 95-134; A. Carlsson, 'A half-century of neurotransmitter research: impact on neurology and psychiatry. Nobel lecture', Bioscience Reports, 21 (2001), 691-790.

30 Ibid.

31 S. Ovallath and B. Sulthana, 'L-DOPA: history and therapeutic applications', Annals of Indian Academy of Neurology, 20 (2017), 185-9; Fahn, 'The history of dopamine and L-DOPA in the treatment of Parkinson's Disease'; Hornykiewicz, 'Dopamine miracle'; Roe, 'From DOPA to Parkinson's Disease'.

32 M. Bliss, The Discovery of Insulin (Chicago: Chicago University Press, 1982); and Jackson, The Age of Stress.

33 H. Y. Meltzer and S. M. Stahl, 'The dopamine hypothesis of schizophrenia: a review', Schizophrenia Bulletin, 2 (1976), 19-76. 
34 D. Ball et al., 'Dopamine markers and general cognitive ability', Neuroreport, 9 (1998), 347-9; S. Nakajima et al., 'The potential role of D3 receptor neurotransmission in cognition', European Neuropsychopharmacology, 23 (2013), 799-813, doi: 10.1016/j.euroneuro.2013.05.006, epub 2013 Jun 20.

35 Quoted in C. D. Camp, 'Neurology', in W. B. Shaw, The University of Michigan, an Encyclopedic Survey (Michigan: University of Michigan Libraries, 1951), pp. 856-7.

36 Porter and Rousseau, Gout; D. Arnold, 'Diabetes in the tropics: race, place and class in India, 1880-1965', Social History of Medicine, 22 (2009), 245-61; Jackson, The Age of Stress.

37 A. J. Lees, 'The pre-morbid personality of patients with Parkinson's Disease', Journal of Neurology, Neurosurgery and Psychiatry, 48 (1985), 97-100; L. Ishihara and C. Brayne, 'What is the evidence for a premorbid Parkinson's personality: a review', Movement Disorders, 28 (2006), 1066-72; W. Poewe, 'The preclinical phase of Parkinson's Disease', in D. B. Calne, R. Horowski, Y. Mizuno, W. Poewe, P. Riederer and M. B. H. Youdim (eds), Advances in Research on Neurodegeneration, vol. 1 (New York: Birkhauser, 1993), pp. 43-5.

38 C. J. Todes and A. J. Lees, "The pre-morbid personality of patients with Parkinson's Disease', Journal of Neurology, Neurosurgery and Psychiatry, 48 (1985), 97-100.

39 Ibid.

40 On biopsychosocial models of disease, see S. Nassir Ghaemi, The Rise and Fall of the Biopsychosocial Model: Reconciling Art and Science in Psychiatry (Baltimore: Johns Hopkins University Press, 2009); R. E. Thayer, The Biopsychology of Mood and Arousal (Oxford: Oxford University Press, 1989); and T. C. Schneirla, 'Problems in the biopsychology of social organisation', Journal of Abnormal and Social Psychology, 41 (1946), $385-402$.

41 C. R. Cloninger, 'A unified biosocial theory of personality and its role in the development of anxiety states', Psychiatric Developments 4 (1986), 167-226.

42 E. J. Devor and R. C. Cloninger, 'Genetics of Alcholism', Annual Review of Genetics, 23 (1989), 19-36; G. Hellinga et al., 'Robert Cloninger', in G. Hellinga et al. (eds), Personalities: Master Clinicians Confront the Treatment of Borderline Personality Disorder (Northvale, NJ and London: Jason Aronson, 2001), pp. 99-120. For discussion of alcohol studies, see Chapter 3.

43 C. R. Cloninger et al., 'The Tridimensional Personality Questionnaire: US normative data', Psychological Reports, 69 (1991), 1047-57; C. R. 
Cloninger et al., 'A psychobiological model of temperament and character', Archives of General Psychiatry, 50 (1993), 975-90; C. R. Cloninger et al., 'Psychometric properties of the temperament and character inventory - revised in a Belgian sample', Journal of Personality Assessment, 85 (2005), 1931-46.

44 P. Heiden, 'Pathological gambling in Parkinson's Disease: what are the risk factors and what is the role of impulsivity?', European Journal of Neuroscience, 45 (2017), 67-72; X. H. Castro-Martínez, 'Behavioral addictions in early-onset Parkinson disease are associated with DRD3 variants', Parkinsonism \& Related Disorders, (2018). pii S1353-8020(18)30011-7.

$45 \mathrm{M}$. Reuter et al., 'The influence of the dopaminergic system on cognitive functioning: a molecular genetic approach', Behavioral Brain Research, 164 (2005), 93-9.

46 M. Reuter et al., 'Identification of first candidate genes for creativity: a pilot study', Brain Research, 1069 (2006), 190-7; D. L. Zabelina, 'Dopamine and the creative mind: individual differences in creativity are predicted by interactions between dopamine genes DAT and COMT', Plos One, 19 January 2016, doi: 10.1371/journal.pone.0146768.

47 The mesolimbic dopaminergic pathway connects the ventral tegmental area in the mid-brain to the ventral striatum of the basal ganglia in the forebrain. The ventral striatum includes the nucleus accumbens and the olfactory tubercle.

48 S. Sapra, 'A combination of dopamine genes predicts success by professional Wall Street traders', Plos One, 7 (January 2012), 1-7, e30844.

49 T. Suhara, 'Dopamine D2 receptors in the insular cortex and the personality trait of novelty seeking', Neuroimage, 13 (2001), 891-5; L. K. Teh et al., 'Tridimensional personalities and polymorphism of dopamine D2 receptor among heroin addicts', Biological Research for Nursing, 14 (2012), 188-96, doi: 10.1177/1099800411405030, epub 2011 May 25; S. W. Savage et al., 'Regulation of novelty seeking by midbrain dopamine D2/D3 signaling and ghrelin is altered in obesity', Obesity (Silver Spring), 22 (2014), 1452-7, doi: 10.1002/oby.20690.

50 See, for example, R. Tomer and J. Aharon-Peretz, 'Novelty seeking and harm avoidance in Parkinson's Disease: effects of asymmetric dopamine deficiency', Journal of Neurology, Neurosurgery and Psychiatry, 75 (2004), 972-5, doi: 10.1136/jnnp. 2003. 024885; V. Kaasinen et al., 'Personality traits and brain dopaminergic function in Parkinson's Disease', Proceedings of the National Academy of Sciences of the USA, 98 (2001), 13272-7, epub 2001 Oct 30. See also, for example, the popular book written by I. Briggs Myers with P. B. Myers, Gifts Differing: Understanding Personality 
Types (Palo Alto, CA: Consulting Psychologists Press, 1980); see also Jackson, The Age of Stress.

51 M. A. Menza et al., 'Dopamine-related personality traits in Parkinson's Disease', Neurology, 43 (1993), 505-8; M. A. Menza et al., 'Personality correlates of $[18 \mathrm{~F}]$ dopa striatal uptake: results of positron-emission tomography in Parkinson's Disease', Journal of Neuropsychiatry and Clinical Neurosciences, 7 (1995), 176-9.

52 Ibid.

53 G. Pluck and R. G. Brown, 'Cognitive and affective correlates of temperament in Parkinson's Disease', Depression Research and Treatment, (2001), Article ID 893873, 8 pages, doi: 10.1155/2011/893873; G. C. Pluck and R. G. Brown, 'Apathy in Parkinson's Disease', Journal of Neurology, Neurosurgery and Psychiatry, 73 (2002), 636-42.

54 A. Schrag, 'Poetic talent unmasked by treatment of Parkinson's Disease', Movement Disorders, 16 (2001), 1175-6.

55 Ibid.

56 Ibid., p. 1176. For parallel discussions about bipolar patients and creativity, see F. K. Goodwin and K. R. Jamison, Manic-Depressive Illness: Bipolar Disorders and Recurrent Depression (Oxford: Oxford University Press, 2007).

57 R. Walker et al., 'Augmentation of artistic productivity in Parkinson's Disease', Movement Disorders, 21 (2006), 285-6.

58 Ibid., p. 285.

59 Ibid., p. 286.

60 For a critique of chemical imbalance theories of psychiatric disease, see J. Moncrieff, The Myth of the Chemical Cure: A Critique of Psychiatric Drug Treatment (London: Palgrave Macmillan, 2008).

61 A. Chatterjee et al., 'Art produced by a patient with Parkinson's Disease', Behavioral Neurology, 17 (2006), 105-8.

62 Ibid., p. 106.

63 Editors, 'Creative and living with Parkinson's? Showcase your work in the Mervyn Peake Awards', Parkinson's Life. A Voice for the International Parkinson's Community, 10 March 2016, available at http:// parkinsonslife.eu/creative-and-living-with-parkinsons-showcase-yourwork-in-the-mervyn-peake-awards/, accessed August 2019.

64 P. Schwingenschuh et al., 'Artistic profession: a potential risk factor for dopamine dysregulation syndrome in Parkinson's Disease?', Movement Disorders, 25 (2010), 493-6, at p. 493.

65 Tolossa et al., 'History of L-DOPA and dopamine agonists in Parkinson's Disease treatment'. 
66 Hornykiewicz, 'A brief history of L-DOPA'; Tolossa et al., 'History of L-DOPA and dopamine agonists in Parkinson's Disease treatment'.

67 H. Czech and L.A. Zeidman, 'Walter Birkmayer, co-describer of L-DOPA and his Nazi connections. Victim or perpetrator?', Journal of the History of the Neurosciences, 23 (2014), 160-91.

68 See the biography of Edward C. Kendall for discussion of the discovery of levothyroxine, available at Nobel Prizes, www.nobelprize.org/nobel prizes/medicine/laureates/1950/kendall-bio.html (2018), accessed August 2019; for work that preceded Kendall on organs of internal secretion by J. F. Gudernatch, see J. D. Furlow and E. S. Neff, 'A developmental switch induced by thyroid hormone: Xenopus laevis metamorphasis', TRENDS in Endocrinology and Metabolism, 17 (2006), 38-45; on insulin see Bliss, The Discovery of Insulin.

69 W. Birkmayer and O. Hornykiewicz, 'The effect of 1-3,4dihydroxyphenylalanine (=DOPA) on akinesia in parkinsonism, Parkinsonism and Related Disorders, 4 (1998), 59-60, at p. 60, originally published in German in Wiener Klinische Wochenschrift, 73 (1961), 787-8.

70 Tolossa et al., 'History of L-DOPA and dopamine agonists in Parkinson's Disease treatment', S3.

71 Ibid.

72 R. Horowski, 'A history of dopamine agonists. From the physiology and pharmacology of dopamine to therapies for prolactinomas and Parkinson's Disease. A subjective view', Journal of Neurotransmission, 114 (2007), 127-34.

73 For the history of receptor theory see V. Quirke, 'Putting theory into practice. James Black, receptor theory and the development of beta-blockers at ICI, 1958-1978', Medical History, 50 (2006), 69-92.

74 Radad et al., 'Short review on dopamine agonists'.

75 C.-H. Chang and A. A. Grace, 'Some dopamine neurons may be more impulsive than others: why differences in receptors and transporters can affect dopamine function in Parkinson's Disease', Movement Disorders, 28 (2013), 1319-20.

76 For historical contextualisation of the emergence of definitions of addiction see V. Berridge, J. Walke and A. Mold, 'From inebriety to addiction: terminology and concepts in the UK 1860-1930', Social History of Alcohol and Drugs, 28 (2014), 88-105.

77 Ibid.

78 Ibid.

79 D. G. MacMahon and G. J. A. Macphee, 'Dopamine agonists and impulse control disorders in Parkinson's Disease', Progress in Neurology and 
Psychiatry, 12 (2008), 5-9. For comparative discussion in diabetes, see Chapter 2.

80 P. Jenner, 'The rationale for the use of dopamine agonists in Parkinson's Disease', Neurology, 45 Suppl. 3 (1995), S6-S12; L. M. Shuman, 'How to succeed in using dopamine agonists in Parkinson's Disease', European Journal of Neurology, 7 Suppl. 1 (2000), 9-13.

81 Shuman, 'How to succeed', p. 13.

82 MacMahon and Macphee, 'Dopamine agonists and impulse control disorders in Parkinson's Disease', S8.

83 Ibid.

84 J. Kulisevsky et al., 'Changes in artistic style and behavior in Parkinson's disease: dopamine and creativity', Journal of Neurology, 256 (2009), 816-20.

85 Ibid., p. 817.

86 For parallel discussion of social as well as physiological considerations in chronic disease management, see M. Moore, 'Food as medicine: diet, diabetes management, and the patient in twentieth century Britain', Journal of the History of Medicine and Allied Sciences, 73 (2018), 150-67.

87 Kulisevsky et al., 'Changes in artistic style', p. 819.

88 S. Pinker, 'Art Movements', CMAJ, 166 (2002), 224, available at www.ncbi.nlm.nih.gov/pmc/articles/PMC99284/, accessed August 2019.

89 Ibid.

90 G. M. Spurll, 'Zen and the art of painting', CMAJ/JAMC, 181 (2009), 175-9.

91 Ibid. See also M. Merleau-Ponty, Phenomenology of Perception (London and New York: Routledge, 2012; 1st edition Paris: Gallimard, 1945).

92 Ibid.

93 Spurll, 'Zen and the art of painting', p. 178.

94 Ibid., p. 178; O. Sacks, Musicophilia: Tales of Music and the Brain (New York: Alfred Knopf, 2007), pp. 270-83.

95 Spurll, 'Zen and the art of painting', p. 90; see also Sacks, Musicophilia, pp. 270-83.

96 See T. Zausner, When Walls Become Doorways: Creativity and the Transforming Illness (New York: Harmony Books, 2006), pp. 21-5.

97 A. Babbitt, 'Movement disorder. Un-still photography', available at www.abproductions.com/movement_disorder/movement_disorder ss.html, accessed August 2019.

98 A. Babbitt, 'The photographer with lousy vision. Confessions of a photo addict', available at www.abproductions.com/about/about.html, accessed August 2019.

99 Ibid. 
100 Ibid.

101 Ibid.

102 Ibid.

103 Aristotle (384-322 BC), Problemata, 30.1. Attributed to Aristotle by Seneca the younger, 'On the tranquility of mind' (17.10).

104 See J. Derrida, 'Cogito and the history of madness', in J. Derrida, Writing and Difference (Chicago: University of Chicago Press, [1967] 1978), pp. 31-63.

105 D. Porter, 'Tremor: the experience of Parkinson's Disease from the shaking palsy to neurobiological compulsion', Canadian Bulletin for the History of Medicine, forthcoming.

106 B. Patoine, 'Facing up to the "New Face" of Parkinson's Disease. An interview with Anthony E. Lang', news release, Dana Foundation website (2012), 1-3 (no longer available).

107 D. Deleu et al., 'An evidence-based review of Dopamine receptor agonists in the treatment of Parkinson's disease', Neurosciences, 7 (2002), 221-31; MacMahon and Macphee, 'Dopamine agonists'; J. A. Borovac, 'Side effects of a dopamine agonist therapy for Parkinson's Disease: a minireview of clinical pharmacology', Yale Journal of Biology and Medicine, 89 (2016), 37-47.

108 Deleu et al., 'An evidence-based review'; MacMahon and Macphee, 'Dopamine agonists'.

109 P. K. Longmore, Why I Burned My Book and Other Essays on Disability (Philadelphia: Temple University Press, 2003). 